\title{
Development and Application of a Validated UHPLC Method for the Determination of Atropine and Its Major Impurities in Antidote Treatment Nerve Agent Auto-Injectors (ATNAA) Stored in the Strategic National Stockpiles
}

\author{
Cheng H. Yen', Adil Mohammad', Miah Schneider', Salwa K. Poole', Bryan Lowry², \\ Brenda W. Mc Curdy1, Patrick J. Faustino², Saeed R. Khan'²* \\ ${ }^{1}$ Office of Regulatory Affairs, Detroit Laboratory, Food and Drug Administration, Detroit, MI, USA \\ ${ }^{2}$ Division of Product Quality Research, Office of Testing and Research, Office of Pharmaceutical Quality, Center for Drug \\ Evaluation and Research, Food and Drug Administration, Silver Spring, MD, USA \\ Email: *saeed.khan2@fda.hhs.gov
}

How to cite this paper: Yen, C.H., Mohammad, A., Schneider, M., Poole, S.K., Lowry, B., McCurdy, B.W., Faustino, P.J. and Khan, S.R. (2017) Development and Application of a Validated UHPLC Method for the Determination of Atropine and Its Major Impurities in Antidote Treatment Nerve Agent Auto-Injectors (ATNAA) Stored in the Strategic National Stockpiles. Pharmacology \& Pharmacy, 8, 15-31. http://dx.doi.org/10.4236/pp.2017.81002

Received: December 22, 2016

Accepted: January 20, 2017

Published: January 23, 2017

Copyright (๑) 2017 by authors and Scientific Research Publishing Inc. This work is licensed under the Creative Commons Attribution International License (CC BY 4.0).

http://creativecommons.org/licenses/by/4.0/ (c) $\underset{\mathrm{EY}}{\text { (i) Open Access }}$

\begin{abstract}
The development and implementation of advanced analytical technologies is essential for extending the expiry for complex drug products stored in the Strategic National Stockpiles. Consequently, a novel Ultra High-Performance Liquid Chromatographic (UHPLC) method has been developed for the analysis of atropine and its respective impurities to support the analytical research platform for auto-injectors. This study is part of a larger research effort to improve the efficiency and broaden the applicability of advanced analytical methods for medical counter-measure medications. The current HPLC compendial methodology for atropine sulfate injection requires an analysis time of 40 minutes for atropine. In comparison, the novel gradient UHPLC method required only 8 minutes to evaluate both atropine and its major pharmaceutical impurities. Improved separation was achieved on a Waters Acquity UHPLC BEH C18 $1.7 \mu \mathrm{m}, 2.1 \times 100 \mathrm{~mm}$ column employing gradient elution of mobile phase solvent $\mathrm{A}\left(0.1 \% \mathrm{H}_{3} \mathrm{PO}_{4}\right)$ and solvent $\mathrm{B}\left(0.1 \% \mathrm{H}_{3} \mathrm{PO}_{4}, 90 \%\right.$ $A C N$, and $10 \% \mathrm{H}_{2} \mathrm{O}$ ). The method was validated according to USP Category I requirements for assay. The daily standard calibration curves were linear over a concentration range from $50 \mu \mathrm{g} / \mathrm{mL}$ to $250 \mu \mathrm{g} / \mathrm{mL}$ with a correlation coefficient of $>0.999$. The detection limit (LOD) and quantitation limit (LOQ) were $3.9 \mu \mathrm{g} / \mathrm{ml}$ and $13.1 \mu \mathrm{g} / \mathrm{ml}$, respectively. Resolution results indicate that atropine and the following impurities, degradants and a preservative can also be separated and analyzed using this proposed method: noratropine, 4,4'-di-hy-
\end{abstract}


droxydiphenyl ether, 2,4'-dihydroxydiphenyl ether, 4-bromophenol, 4-hydroxyatropine, tropic acid, apoatropine $\mathrm{HCl}$, atropic acid, hydroquinone, nitroethane, phenol and catechol. The UHPLC method demonstrated enhanced selectivity and significantly reduced the analysis time when compared with the traditional USP compendial HPLC method. The method was successfully applied to the evaluation of atropine in ATNAA auto-injectors lots from the Strategic National Stockpiles.

\section{Keywords}

Atropine Sulfate, Atropine, ATNAA, SLEP, UHPLC, Impurities

\section{Introduction}

The Department of Defense (DoD) and Food and Drug Administration's (FDA) Shelf Life Extension Program (SLEP)

(http://www.fda.gov/EmergencyPreparedness/Counterterrorism/MedicalCounte rmeasures/MCMLegalRegulatoryandPolicyFramework/ucm411446.htm) represents a unique partnership between the DoD and the FDA's Center for Drug and Evaluation Research (CDER) and the Office of Regulatory Affairs (ORA). This program is designed to save the federal government and the US taxpayer significant monetary resources by selecting products purchased by DoD and testing them for potency and stability to extend their effective shelf life beyond expiry. FDA has developed and operated a scientifically sound program that can determine whether, and for how long, a specific lot of a specific drug product will continue to meet applicable quality standards after it has reached its labeled expiration date [1]. To maintain a state of readiness, the military, under controlled conditions, store large stockpiles of pharmaceuticals sealed in their original container closures. A system of extending the functional shelf life of these drug products beyond their original expiration date was initiated to reduce the high cost of replacing these stockpiles. Based on a comprehensive testing program, the shelf life of several drug products has been extended on a lot-by-lot basis. This program has resulted in substantial savings to the military. A recent study has shown that each dollar spent on SLEP results in $\$ 13$ to $\$ 94$ saved on reacquisition costs [2]. For many years, the FDA's Detroit field laboratory has been an important partner with the Center for Drug Evaluation and Research in the analysis of various medical products stored (https://chemm.nlm.nih.gov/chempack.htm) for the DoD as part of the Strategic National Stockpile (SNS) program [3].

Drugs tested in this program range from antibiotics to antidotes for various poisoning agents [3]. One of the important medical products that have been analyzed by FDA is ATNAA (Antidote Treatment Nerve Agent Auto-Injector), which is currently being stockpiled by the military

(http://archive.defense.gov/news/newsarticle.aspx?id=120780) for the treatment 
of nerve agent intoxication, such as organophosphorus nerve agent poisoning. ATNAA is a medical-counter-measure that contains two main components: atropine and pralidoxime chloride (Figure 1).

ATNAA is an auto injector drug-device product designed to deliver a prefilled, single intramuscular dose of atropine and pralidoxime chloride in a self-contained unit [4]. The auto injector is designed with two internal chambers, one on top of the other. The top chamber contains the drug atropine, and the bottom chamber holds pralidoxime chloride. Once activated, it releases the parenteral drugs into the body. Atropine Injector is indicated for use as a result of exposure to life-threatening poisoning by organophosphorus nerve agents. These nerve agents cause phosphorylation of the cholinesterase enzyme that leads to inactivation of muscarinic acetylcholine receptor [5]. Atropine is used as the symptomatic treatment that is able to decrease the effects of the accumulated acetylcholine on the cholinergic receptors [5]. Also, treatment of patients by ATNAA auto-injectors takes approximately half the time than a traditional injection using a needle and syringe [6]. Another important part of this combination drug-device product is the pralidoxime injector, which is effective in reversing the action of organophosphate poisoning. It inhibits binding of an organophosphate agent with the acetylcholinesterase enzyme receptor [7] [8]. Studies have proven that both compounds atropine and pralidoxime are very effective in cases of nerve agent poisoning [9] [10].

Pralidoxime chloride has its most critical effect in relieving paralysis of the muscles of respiration. Because pralidoxime is less effective in relieving depression of the respiratory center, atropine is always required concomitantly to block the effect of accumulated acetylcholine at this site. Pralidoxime relieves muscarinic signs and symptoms, salivation, bronchospasm, etc.; but this action is relatively unimportant since atropine is adequate for this purpose Published reports have established the safety and efficacy of atropine and pralidoxime chloride used separately, as well as the safety and increased efficacy of atropine and pralidoxime chloride when administered concomitantly in the treatment of nerve agent poisoning in humans [11].

Numerous stability studies have shown that pralidoxime and atropine sulfate is remarkably stable at room temperature measured by HPLC after 10 years [12]

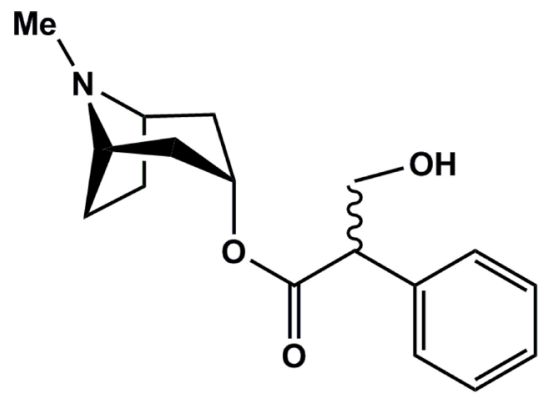

(a)

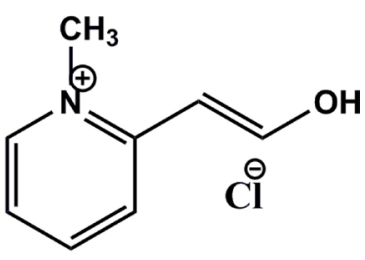

(b)

Figure 1. Components of ATNAA auto injector: (a) Atropine and (b) Pralidoxime Chloride [4]. 
[13]. However, the stability of the atropine drugs in these auto-injectors has been an area of concern and has been studied [14]. Therefore, an improved analytical test method used for the determination of atropine and its impurities in the pharmaceutical dosage form is essential in order to monitor and control the impurities in the drug substances, particularly as applied to cases of extended storage. Examples of impurities found in atropine include tropic acid and apoatropine (Figure 2). These two compounds result from degradation of the active pharmaceutical ingredient when it is stored for a period of time [15]. On the one hand, acidic conditions can result in ester hydrolysis, leading to the formation of tropine and tropic acid (which can lose water to create atropic acid) [15]. On the other hand, basic conditions can cause atropine to lose water, resulting in the formation of apoatropine [15]. Atropine is also capable of decomposing into atropic acid [16]. Noratropine can be generated by the oxidative $\mathrm{N}$-demethylation of atropine in an aqueous solution, with the presence of potassium permanganate [17]. Along with noratropine, other metabolites of atropine include 4,4'-dihydroxydiphenyl ether, $2,4^{\prime}$-dihydroxydiphenyl ether, and 4-hydroxyatropine is also being reported. It is

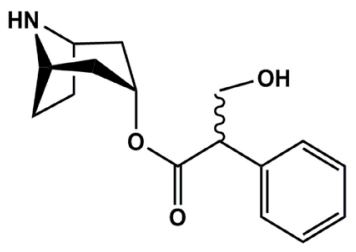

(Noratropine)

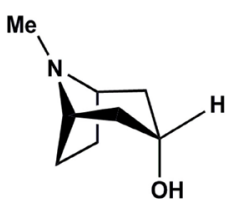

(Tropine)

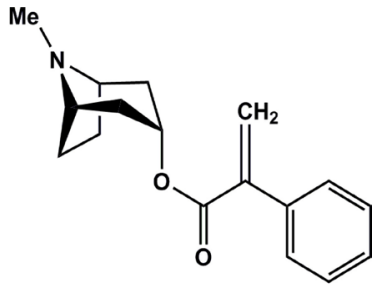

(Apoatropine)<smiles>CN1[C@H]2CC[C@@H]1C[C@@H](OC(=O)C(SCO)c1ccc(O)cc1)C2</smiles>

(4-Hydroxyatropine)<smiles>Oc1ccc(Oc2ccc(O)cc2)cc1</smiles>

(4,4'-Dihydroxydiphenyl ether)<smiles>Oc1ccccc1O</smiles>

(Catechol)

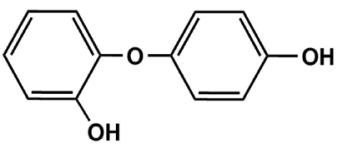

(2,4'-Dihydroxydiphenyl ether)<smiles>Oc1ccccc1</smiles>

(Phenol)<smiles>C=C(C(=O)O)c1ccccc1</smiles>

(Atropic acid)<smiles>O=C(O)C(CO)c1ccccc1</smiles>

(Tropic acid)

Figure 2. Major impurities of atropine including phenol (added to ATNAA formulation). 
important to understand the pharmaceutical chemistry to anticipate the separation and analysis requirements of these complex set of impurities [18].

In the past, analytical techniques such as HPLC have been employed for the analysis of atropine and its impurities [19]-[24]. Due to the complex nature and variability of the impurities in this medical counter measure drug product, it was difficult to separate out all the related compounds and degradation impurities of atropine by available HPLC methodology [25]. However, when acceptable chromatographic resolution was achieved using HPLC, the analysis time for the determination of atropine and its impurities (apoatropine, tropic acid and atropic acid) was quite long (40 - 70 minutes) (Figures 3-6). As a result of the

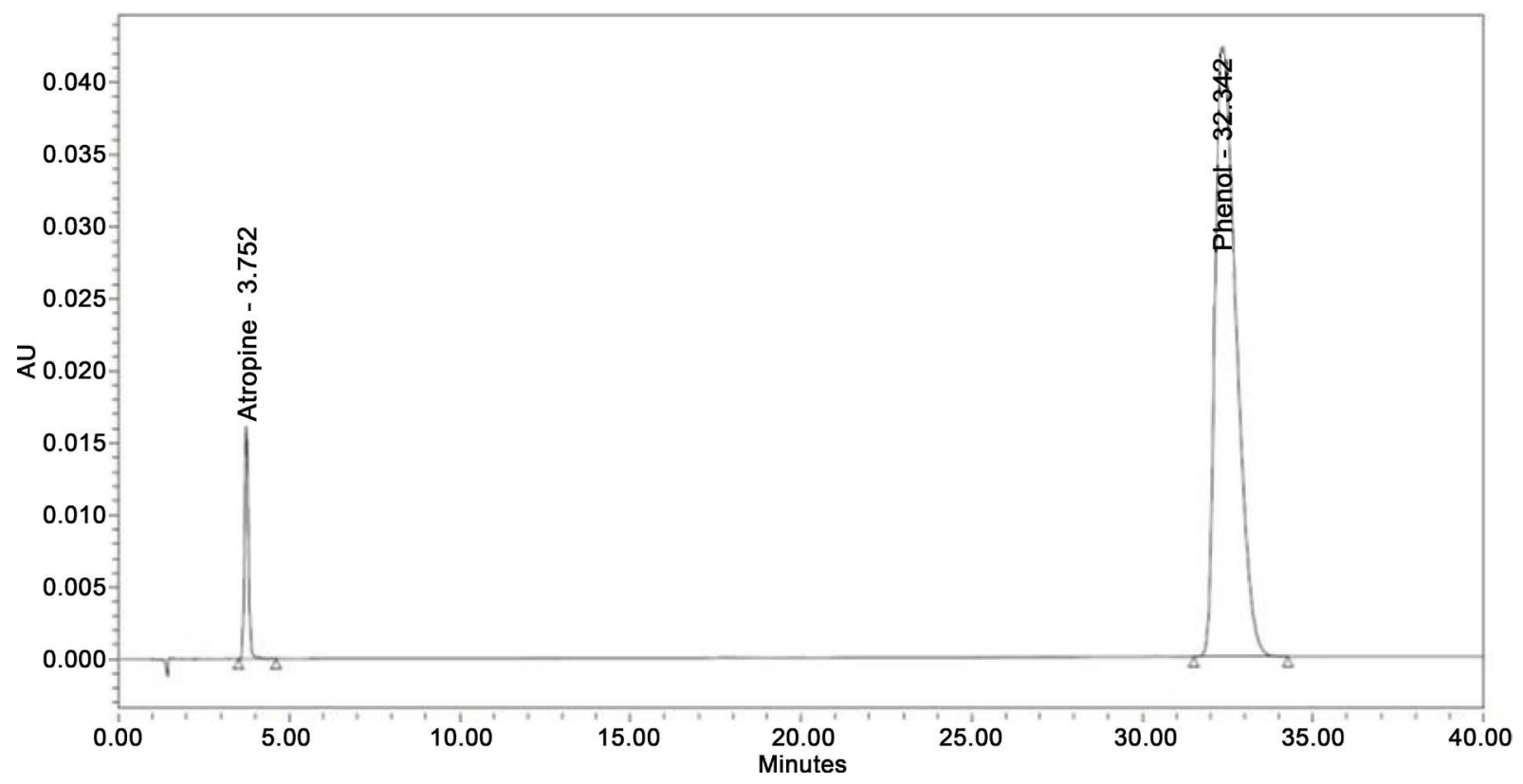

Figure 3. HPLC (USP 37) chromatogram of atropine and phenol standards.

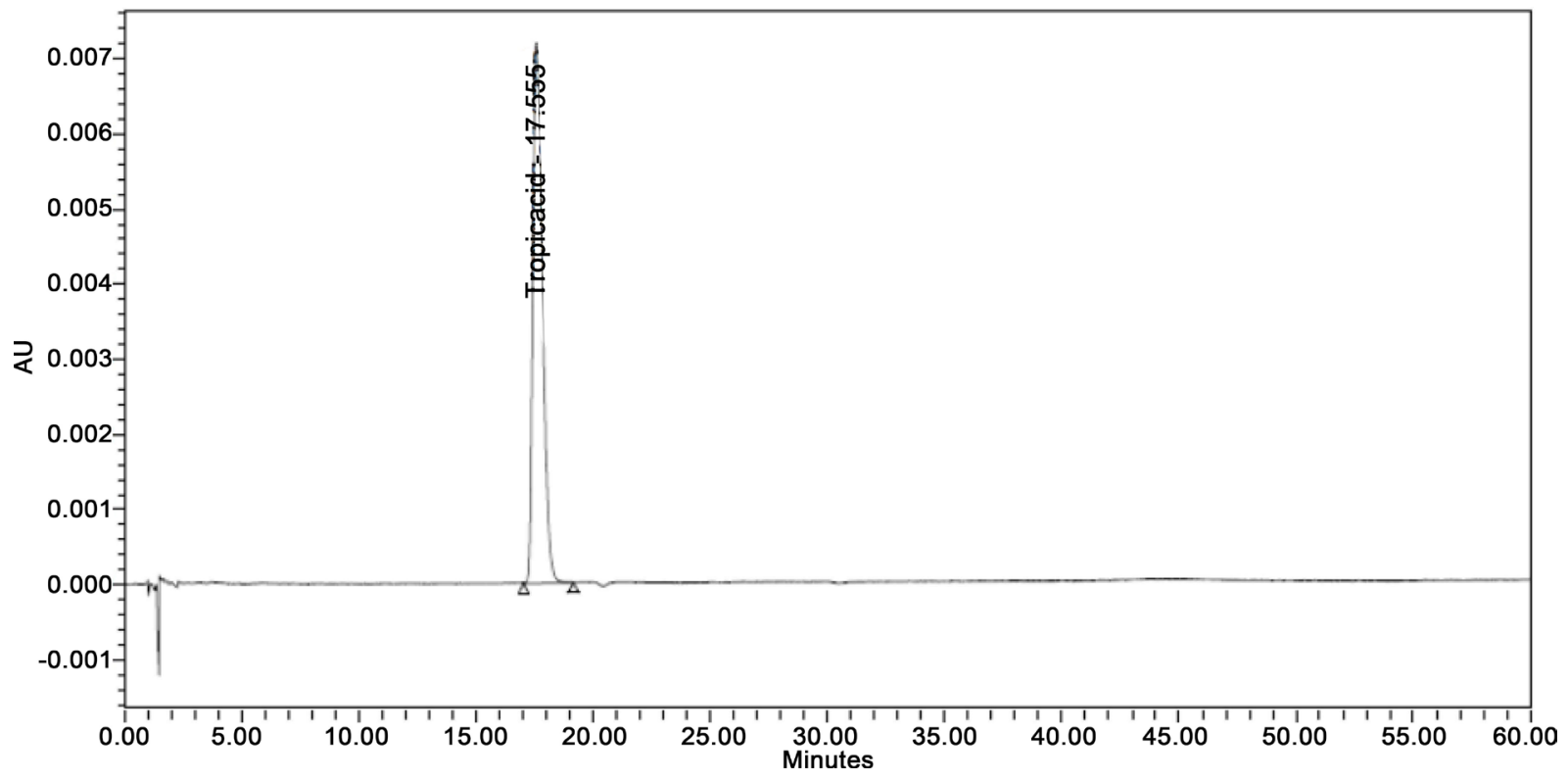

Figure 4. HPLC (USP 37) chromatogram of tropic acid standard. 


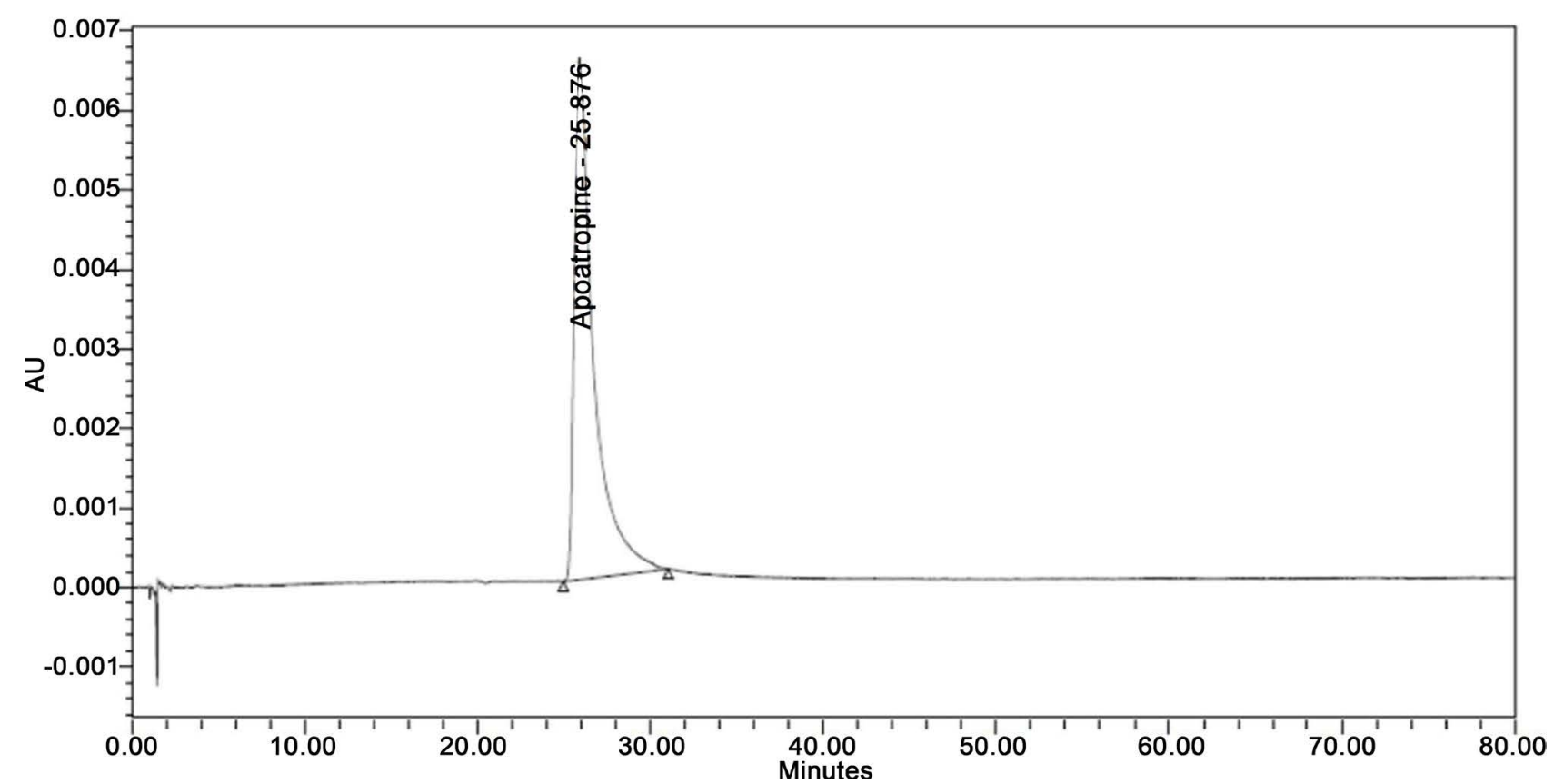

Figure 5. HPLC (USP 37) chromatogram of apoatropine $\mathrm{HCl}$ standard.

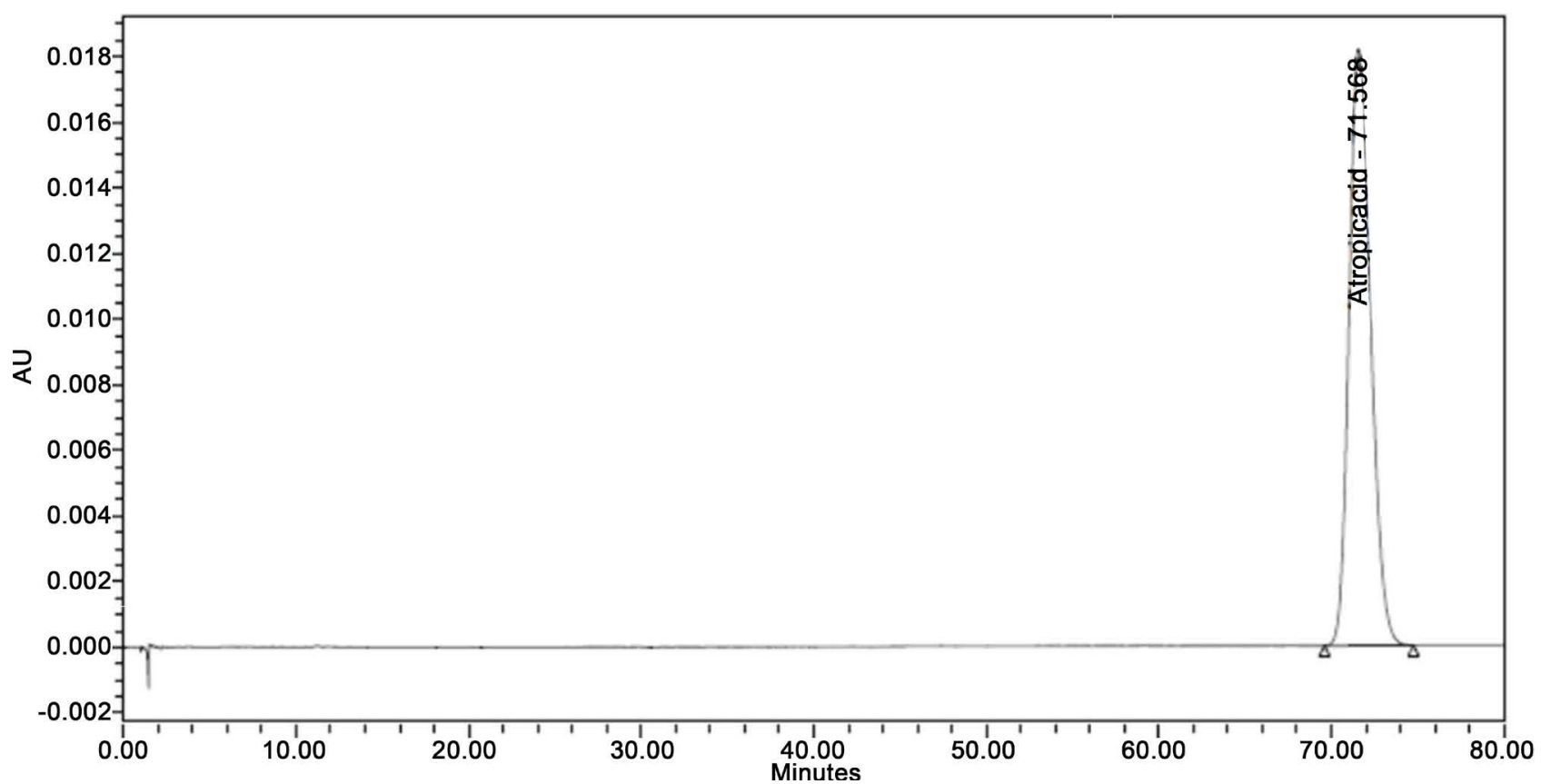

Figure 6. HPLC (USP 37) chromatogram of atropic acid standard.

introduction of new high resolution chromatographic techniques such as UHPLC, a new, simple, selective, and efficient method with an extended linear range and enhanced sensitivity for atropine and its related impurities has been developed. UHPLC is a relatively recent technique in liquid chromatography that is being more broadly applied to complex pharmaceutical drug products. The primary advantages for wide scale pharmaceutical use include significant reductions in analysis, time, resolution and solvent consumption [26]. The literature indicates that a UHPLC system allows for nearly a 10-fold decrease in 
analysis time as compared to the conventional high-performance HPLC system using $5 \mu \mathrm{m}$ particle size analytical columns, and approximately threefold decrease in analysis time in comparison with $3 \mu \mathrm{m}$ particle size analytical columns without compromise on overall separation [27]-[32]. In this study, the average particle size for the UHPLC columns was 1.7 microns, which is significantly smaller than the typical 5 - 10 micron particle size of traditional HPLC columns. The smaller particles provide increased efficiency and enhanced resolution, while managing significantly higher system back-pressure with improved engineering of the UHPLC and the overall system design [26]. Collectively these advantages provide significant reasons in support of the implementation of advanced chromatographic technologies to monitor complex drug products.

In this paper, we present a validated method for the rapid quantitative determination of atropine and its potential impurities based on UHPLC methodology. Until now, no exhaustive UHPLC chromatographic method for analysis of atropine and its potential impurities has been described. Previous studies have analyzed atropine by itself without impurities using a UHPLC method [33]. The developed UHPLC method was validated according to USP <1225> [34] with respect to specificity, limit of quantitation (LOQ), linearity, precision, and accuracy. The method was successfully applied for the analysis of atropine and its impurities in an auto-injector drug product.

\section{Materials and Methods}

\subsection{Chemicals and Reagents}

Acetonitrile (UPLC grade), phosphoric acid and glacial acetic acid were purchased from Fisher Scientific, (Fair Lawn, NJ). Sodium acetate, catechol, nitroethane, hydroquinone, noratropine, 2-bromophenol, 4-bromophenol and tropic acid were purchased from Sigma Aldrich (St. Louis, MO). Tetra butyl hydrogen sulfate was purchased from Acros (Pittsburgh, PA) and $5 \mathrm{~N}$ sodium hydroxide from EMD chemicals (Darmstadt, Germany). Atropine sulfate United States Pharmacopeia reference standard was purchased from USP (Rockville, MD). Apoatropine $\mathrm{HCl}$ and atropic acid were purchased from Meridian (Columbia, MD). All other chemicals were of reagent grade, and the water was obtained from the Thermo Scientific Barnstead Genpure Pro and Millipore Milli-Q water systems.

\subsection{Instrumentation and Chromatographic Conditions}

\subsubsection{HPLC Methodology}

A Waters Alliance 2695 HPLC (Milford, MA) with 2489 UV/Visible detector, solvent manager and sample manager was used. Separation was achieved on HPLC C-18 column, $4.6 \times 250 \mathrm{~mm} 5$-micron 80A. Column temperature was mentioned at $25^{\circ} \mathrm{C}$. The chromatographic conditions for the USP 37 HPLC method were the following: flow rate of $2 \mathrm{~mL} / \mathrm{min}$, isocratic run, $100 \%$ mobile phase consisting of $5.1 \mathrm{~g}$ of tetrabutylammonium hydrogen sulfate with $50 \mathrm{~mL}$ of acetonitrile, dilute with Acetate buffer to $1 \mathrm{~L}$ and adjust $\mathrm{pH}$ to 5.5 with $5 \mathrm{~N}$ 
$\mathrm{NaOH}$. The HPLC method was validated (data not shown) and then transferred to UHPLC.

\subsubsection{UHPLC Methodology}

A Waters Acquity H-Class UHPLC (Milford, MA) with a photo-diode array (PDA) detector, quaternary solvent and sample manager was used. Separation was achieved on a Waters Acquity (Wexford, Ireland) BEH C18 $1.7 \mu \mathrm{m}, 2.1 \times$ $100 \mathrm{~mm}$ column. The chromatographic conditions for the method were the following: flow rate of $0.55 \mathrm{~mL} / \mathrm{min}$, mobile phase consisting of solvent $\mathrm{A}(0.1 \%$ $\left.\mathrm{H}_{3} \mathrm{PO}_{4}\right)$ and solvent $\mathrm{B}\left(0.1 \% \mathrm{H}_{3} \mathrm{PO}_{4}, 90 \%\right.$ acetonitrile, $\left.10 \% \mathrm{H}_{2} \mathrm{O}\right)$ with the following gradient (Table 1 ).

The column temperature was controlled at $50^{\circ} \mathrm{C}$, and the injection volume was $1.0 \mu \mathrm{L}$. The UV detection wavelength was $220 \mathrm{~nm}$, and the run time was 7 minutes.

\subsection{Preparation of Standards Solutions}

\subsubsection{Calibration Standards}

The initial stock standard calibration solution was created with a concentration of approximately $250 \mu \mathrm{g} / \mathrm{mL}$. $6.25 \mathrm{mg}$ of atropine sulfate was weighed out in a $25.0 \mathrm{~mL}$ volumetric flask. The flask was then filled with Milli-Q water to two-thirds volume with water and then sonicated and shaken for 5 minutes at $37^{\circ} \mathrm{C}$ and 75 RPM. Using the stock standard solution $(\sim 250 \mu \mathrm{g} / \mathrm{mL})$, the following calibration solutions were then prepared by serial dilution: 200, 100, 75 and $50 \mu \mathrm{g} / \mathrm{mL}$.

\subsubsection{Quality Control Standards}

The initial stock QC solution was created with a concentration of approximately $250 \mu \mathrm{g} / \mathrm{mL}$. $6.25 \mathrm{mg}$ of atropine sulfate was weighed out in a $25.0 \mathrm{~mL}$ volumetric flask. The flask was then filled with deionized Milli-Q water to two-thirds volume with water and then sonicated and shaken for 5 minutes $37^{\circ} \mathrm{C}$ and $75 \mathrm{RPM}$. Using the stock standard solution $(250 \mu \mathrm{g} / \mathrm{mL})$, the following quality control standards were then prepared by serial dilution: 100 and $50 \mu \mathrm{g} / \mathrm{mL}$.

\subsubsection{Impurity Standard Solution (Resolution Solution)}

The following compounds were weighed accurately and separately into $25 \mathrm{~mL}$ volumetric flasks each and diluted up to volume with Milli-Q water (scale down

Table 1. UHPLC gradient overview.

\begin{tabular}{ccc}
\hline Time (minutes) & Solvent A (\%) & Solvent B (\%) \\
\hline 0.00 & 84 & 16 \\
2.20 & 84 & 16 \\
2.21 & 65 & 35 \\
5.00 & 65 & 35 \\
5.10 & 84 & 16 \\
7.00 & 84 & 16 \\
\hline
\end{tabular}


as necessary): $3.0 \mathrm{mg}$ noratropine, $1.5 \mathrm{mg}$ hydroquinone, $1.5 \mathrm{mg}$ catechol, $3.0 \mathrm{mg}$ of 2,4'-dihydroxydiphenyl, $3.0 \mathrm{mg}$ of 4,4'-dihydroxydiphenyl ether, $3.0 \mathrm{mg}$ of nitroethane, $1.5 \mathrm{mg}$ of tropic acid, $1.75 \mathrm{mg}$ of apoatropine, $1.5 \mathrm{mg}$ of atropic acid, and $3.0 \mathrm{mg}$ of 4-bromophenol.

1) To create the final impurity mix, 2 volumes of noratropine were diluted with 1 volume of each impurity standard into separate flasks.

2) The individual impurities can be stored for later use, but the final impurity mix must be mixed fresh prior to use.

\subsection{Sample Preparation}

Sample content from one ATNAA injector equivalent to approximately $2.1 \mathrm{mg}$ atropine) was transferred into a $10.0 \mathrm{~mL}$ volumetric flask and diluted up to volume with Milli-Q water. System suitability experiments were performed to demonstrate linearity, precision, and accuracy, as per USP <621> Chromatography [35]. Three lots of ATNAA injectors were tested in this study.

\subsection{Analytical Method and Validation}

The method was validated according to the United States Pharmacopeia $<1225>$ Validation of Chromatographic Methods-Category 1 requirements for Assay as well as a limits test for the impurities. The following validation characteristics were addressed: precision, accuracy, linearity, range and specificity.

\subsubsection{System Suitability Standard}

System suitability standard solution was prepared daily from the stock atropine sulfate solution and the phenol standard solution $(0.1971 \mathrm{mg} / \mathrm{mL}$ and 0.2467 $\mathrm{mg} / \mathrm{mL}$ respectively). System suitability was determined from six replicate injections of the system suitability standard before sample analysis. Based on USP $<621>$ and regulatory specifications for limits, the acceptance criteria were the following: less than $2 \%$ relative standard deviation (RSD) for the peak area of six consecutive injections, greater than 2000 theoretical plates, USP tailing factor less than 2.0, resolution of peaks greater than 2, and capacity factor ( $k$ ') greater than 1.0 .

\subsubsection{Linearity and Range}

Standard calibration curves were prepared with five calibrators over a concentration range of $50-250 \mu \mathrm{g} / \mathrm{mL}(50,75,100,200$ and $250 \mu \mathrm{g} / \mathrm{mL})$ for atropine sulfate. The data of peak area versus drug concentration were treated by linear least square regression analysis. The standard curves were evaluated for intraand inter-day linearity. The analytical range was established by the highest and lowest concentrations of analyte where acceptable linearity, accuracy and precision were obtained.

\subsubsection{Accuracy and Precision}

Accuracy and precision of the method were determined for atropine sulfate: the QC standard samples at three concentrations of atropine (low QC 50, 
intermediate QC 100, and high QC $250 \mu \mathrm{g} / \mathrm{mL}$ Precision was expressed as a coefficient of variation percentage $(\mathrm{CV} \%)$ of the analyte peak.

\subsubsection{Specificity}

Specificity of the method was determined by observing that there were no coeluents with atropine or its major impurities.

\subsection{Analysis of Drug Products}

Three different lots of ATNAA auto-injectors stored in the SNS were evaluated for potency and impurities of atropine.

\section{Results and Discussion}

The UHPLC System is an advanced chromatographic technology that is designed to improve the resolution of complex chemical mixtures. This is generally achieved by minimizing band spreading within column and taking advantage of sub 2 micron particle size columns. UHPLC technology presents an important opportunity for the separation, identification and determination of major and minor or potential impurities of atropine present in parenteral pharmaceutical dosage forms. This study supports the goal of advancing the research platform for auto-injectors to enhance regulatory monitoring capabilities and control risk for stockpiled drug products. Here, it was demonstrated the potential minor and major impurities were not able to be efficiently resolved by HPLC methodology. However, following a simple method transfer, potential minor and major impurities were effectively resolved by UHPLC (Figures 2-5).

\subsection{Development and Optimization of UHPLC Chromatographic Method}

The primary objective of the present study was aimed at developing a sensitive, precise and accurate UHPLC method for analysis of atropine and its respective impurities in auto-injector drug products. Initially, the atropine assay was performed using the traditional USP 37 method for atropine sulfate injection to establish a baseline for chromatographic outcomes including analysis time, tailing, selectivity, resolution, etc. As seen in Figures 2-5, the HPLC analysis time is 40 minutes for the run to resolve the atropine and phenol peaks; but the analysis time can take over 70 minutes when trying to resolve the atropic acid peak as well (Figure 3). The primary preservative used for ATNAA is phenol, whose peak elutes at approximately 32 minutes. Other impurities of interest (see Figures 4-6) include the following: tropic acid (17.6 min retention time), apoatropine $\mathrm{HCl}$ (25.9 min retention time) and atropic acid (71.6 min retention time).

In order to achieve enhanced separation, for both major and minor impurities and a less complex mobile phase, the USP 37 method was transferred to a UHPLC system without salt composition in the mobile phase. Selected gradient were screened to resulting in the noted gradient that resolved all the impurities with dramatically increased efficiency.

The USP system suitability test was conducted daily and the method was 
validated according to USP $<1225>$ validation of chromatographic methods for the UHPLC method. The system suitability test included also included the impurities and the results indicated no change in retention time for the respective impurities. This test provided assurance that the method was reproducible despite the significant gradient change between 2.0 and 2.1 minutes. The resolution parameter Rs for atropine and tropic acid was evaluated and found to be consistent over the three day validation period. Ruggedness testing was conducted with multiple analysts and multiple instruments using the system suitability test and the method was found to be rugged.

The UHPLC method was able to achieve the separation of all four impurities including tropic acid $1.5 \mathrm{~min}$ vs. $18 \mathrm{~min}$, apoatropine $\mathrm{HCl} 3 \mathrm{~min}$ vs. $26 \mathrm{~min}$, and most notably atropic acid $3 \mathrm{~min}$ vs. $72 \mathrm{~min}$. The chromatography is highlighted in Figures 7-9. The following impurities were also analyzed simultaneously using the UHPLC method: noratropine, 4,4-dihydroxydiphenyl ether, 2,4-dihydroxydiphenyl ether, 4-bromophenol, 4-hydroxyatropine, tropic acid, apoatropine $\mathrm{HCl}$, atropic acid, hydroquinone, nitroethane, phenol and catechol. The chromatographic results for the various impurities are shown in Figure 7 and the quantitative analyte and impurity profiles.

\subsection{System Suitability}

The system suitability test evaluates the daily operating parameters of the analytical system including the resolution between different peaks of interest. All critical parameters tested met the acceptance criteria on all days (Table 2).

The system suitability test for the analytical UHPLC method established instrument performance operating parameters such as retention time, peak area, capacity factor, and USP tailing factor for the atropine sulfate peak. All validation

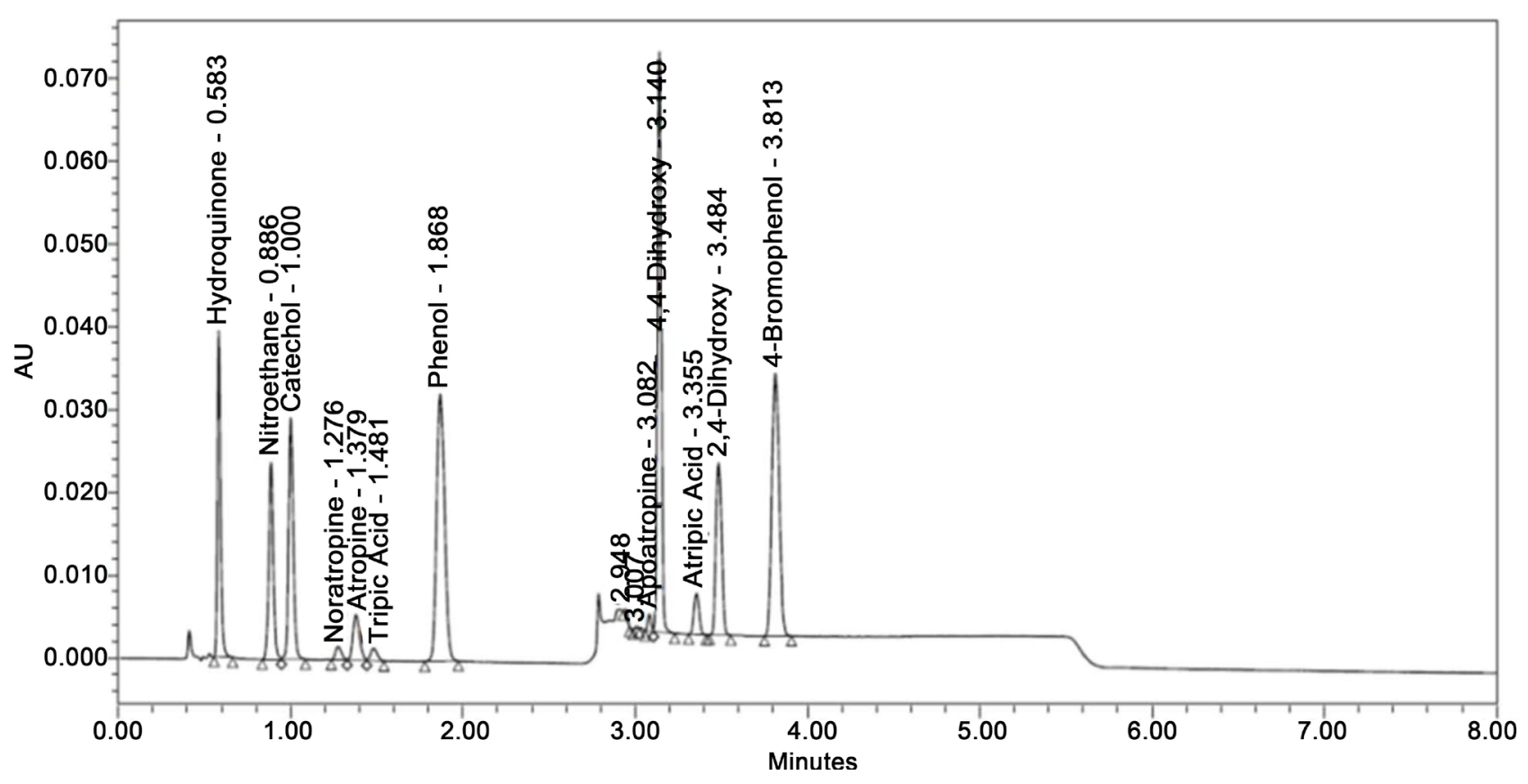

Figure 7. UHPLC resolution solution chromatogram for ATNAA and its impurities. 


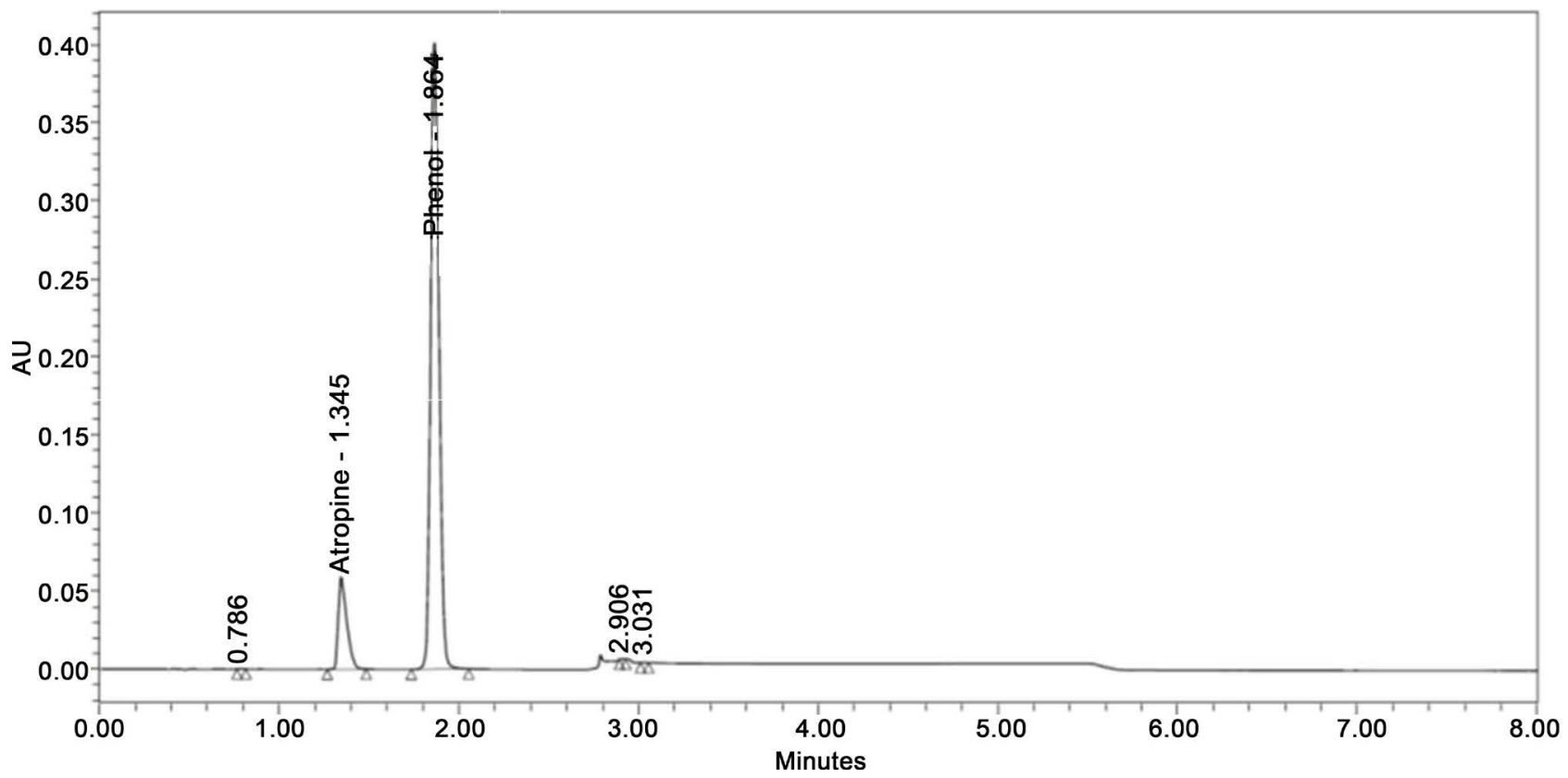

Figure 8. Chromatogram of atropine sulfate standard with phenol standard.

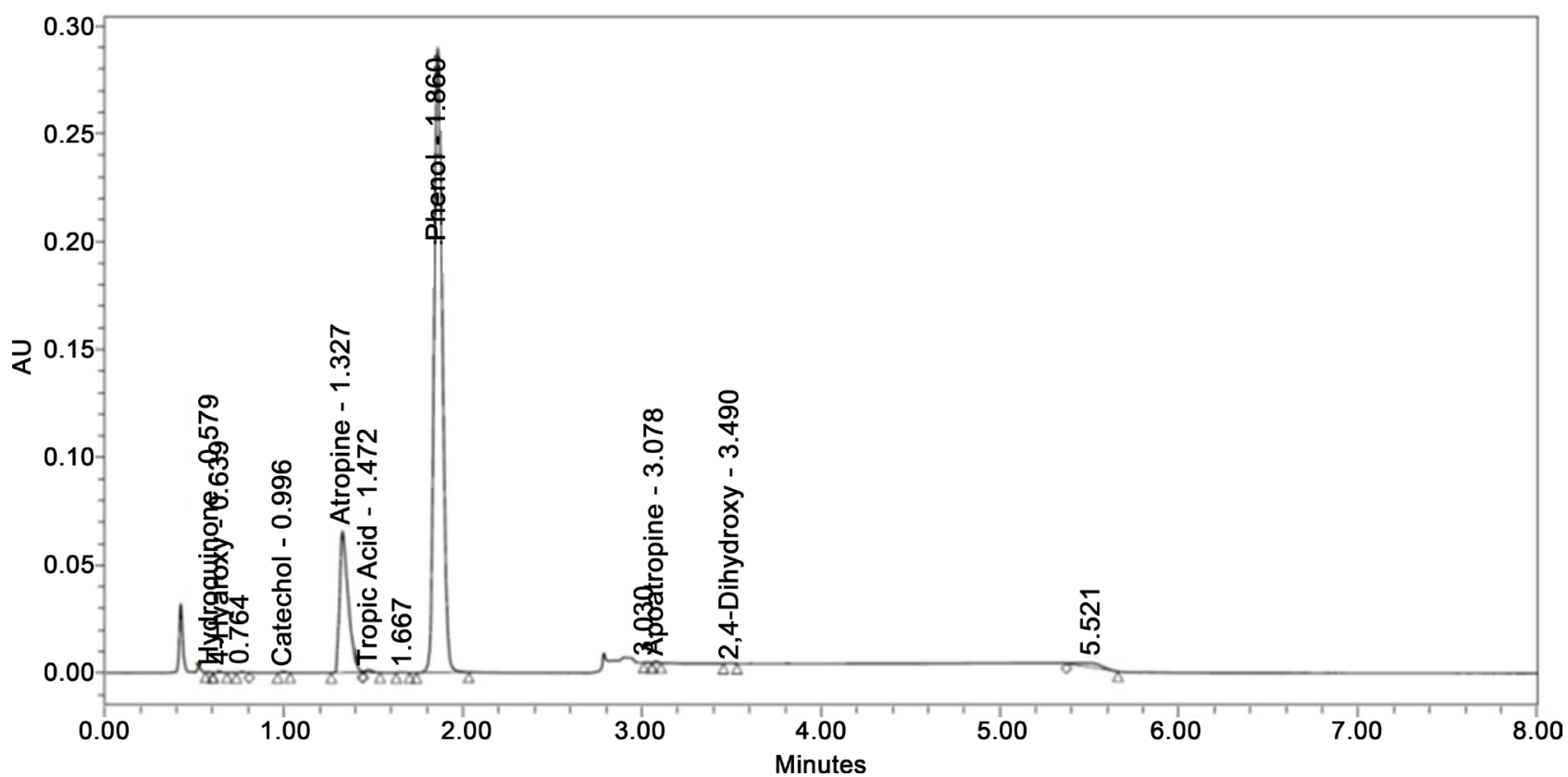

Figure 9. Chromatogram of ATNAA auto-injector sample.

Table 2. System suitability test results $(n=6)$.

\begin{tabular}{cccccc}
\hline USP criteria & Specifications & Day 1 & Day 2 & Day 3 & Pass/Fail \\
\hline Retention time & RSD $\leq 2.0 \%$ & 1.3 & 1.3 & 1.3 & Pass \\
Capacity factor $\mathrm{k}^{\prime}$ & $>1.0$ & 1.6 & 1.6 & 1.6 & Pass \\
Area & $\mathrm{RSD} \leq 2.0 \%$ & 0.2 & 0.2 & 0.2 & Pass \\
Theoretical plates & $>2000$ & 4208 & 4238 & 4215 & Pass \\
USP tailing & $<2.0$ & 1.8 & 1.8 & 1.8 & Pass \\
Resolution $^{*}$ & $>2.0$ & 3.2 & 3.3 & 3.4 & Pass \\
\hline
\end{tabular}

${ }^{*}$ Resolution calculated based on atropine sulfate and tropic acid peak. 
parameters tested met the acceptance criteria on all days.

\subsection{Method Validation}

The following method validation characteristics were addressed for atropine sulfate: accuracy, precision, specificity, linearity and range. The validation characteristics met the acceptance criteria for USP Category I.

\subsubsection{Linearity and Range}

Linearity of the method was confirmed by preparing atropine sulfate standard curves for the analytical range of $50-250 \mu \mathrm{g} / \mathrm{mL}$. A correlation between analyte peak area and concentration of the drug was observed with $r^{2} \geq 0.9999$ for the standard curves (Table 3 ).

\subsubsection{Accuracy and Precision}

Accuracy and precision were established across the analytical range for atropine sulfate. The accuracy and intra- and inter-day precision were calculated from the QC samples for atropine sulfate. Results for the intra-day accuracy of atropine sulfate are summarized in Table 4.

\subsubsection{Specificity}

The analysis of the mobile phase (solvent A: $0.1 \% \mathrm{H}_{3} \mathrm{PO}_{4}$, solvent B: $0.1 \% \mathrm{H}_{3} \mathrm{PO}_{4}$, $90 \%$ acetonitrile, $10 \% \mathrm{H}_{2} \mathrm{O}$ ) solution showed the absence of any major peaks beyond the void volume (Figure 6). Due to the observable absence of any co-eluting peaks, this method was shown to be specific for atropine sulfate.

\subsubsection{Drug Product Evaluation}

The validated method was successfully applied for the evaluation of three different lots of ATNAA as shown in Table 5.

Table 3. Parameters and linearity of atropine sulfate UHPLC calibration curves.

\begin{tabular}{cccccc}
\hline Standard curve & Range $(\mu \mathrm{g} / \mathrm{mL})$ & Calibrators & Slope & $y$-intercept & $R^{2}$ value \\
\hline Day 1 & $50-250$ & 5 & 993.30 & -2079.5160 & 1.0000 \\
Day 2 & $50-250$ & 5 & 999.60 & -2489.2502 & 1.0000 \\
Day 3 & $50-250$ & 5 & 1002.79 & -2022.8564 & 1.0000 \\
\hline
\end{tabular}

Table 4. Atropine sulfate accuracy and precision: drug substance (\% recovery, $\mathrm{n}=3$ ).

\begin{tabular}{ccccc}
\hline & & \multicolumn{2}{c}{ Validation (QC) solutions $(\mu \mathrm{g} / \mathrm{mL})$} \\
\cline { 3 - 4 } & & 50 & 100 & 250 \\
\hline Accuracy (\% recovery) & Day 1 & 100.6 & 100.0 & 100.1 \\
& Day 2 & 101.4 & 100.4 & 100.9 \\
& Day 3 & 100.5 & 99.7 & 100.5 \\
\hline Precision (\% RSD) & Day 1 & 0.4 & 0.4 & 0.4 \\
& Day 2 & 0.6 & 0.2 & 0.4 \\
\hline
\end{tabular}


Table 5. Test results for atropine assay and its impurities in ATNAA auto injector.

\begin{tabular}{ccccc}
\hline Test & Specifications & Lot 1 & Lot 2 & Lot 3 \\
\hline Atropine (\% declared) & (90 - 115)\% & 99.6 & 97.9 & 96.9 \\
Phenol (mg/mL) & NLT 0.5 mg/mL & 2.99 & 3.03 & 3.02 \\
\% Tropic acid & NMT 2.0\% & 1.06 & 1.01 & 0.98 \\
\% Apoatropine & NMT 0.5\% & 0.23 & 0.22 & 0.2 \\
\% Atropic acid & NMT 0.5\% & ND & ND & ND \\
\% Hydroquinone & NMT 2.0\% & 0.05 & 0.04 & 0.04 \\
\% Nitroethane & NMT 2.0\% & ND & ND & ND \\
\% Catechol & NMT 1.0\% & 0.13 & 0.09 & 0.1 \\
\% Noratropine & NMT 2.0\% & ND & ND & ND \\
\% 4,4'-Dihydroxy & NMT 1.0\% & 0.06 & 0.06 & 0.06 \\
\% 2,4'-Dihydroxy & NMT 1.0\% & 0.05 & 0.05 & 0.04 \\
\% 4-Bromophenol & NMT 2.0\% & 0.05 & 0.05 & 0.05 \\
\% 4-Hydroxy & NMT 1.0\% & 0.25 & 0.21 & 0.21 \\
\hline
\end{tabular}

Each of the 3 separate lots met the USP specifications for potency and impurity limits. The method takes advantage of the resolution enhancement of UHPLC to fully describe the related and degradation and excipient impurities in a complex formulation auto-injector drug product.

\section{Conclusions}

The compendial HPLC method for atropine was implemented and evaluated for efficiency and suitability to assess an atropine auto-injector drug product and its impurity profile. The USP 37 HPLC method was found to require analysis run times up to 80 minutes, especially in product samples with the associated complex impurity profile. A simple, sensitive and accurate UHPLC method was developed for the efficient resolution and quantitatation of atropine and its respective impurities of atropine auto-injector formulations. The developed UHPLC method was found to be rapid ( 8 min run time), accurate and sensitive. The analytical method was validated to ensure compliance in accordance with USP $<1225>$ guidelines.

The UHPLC method was directly compared with the compendial HPLC method described in the USP37. The proposed UHPLC method demonstrated enhanced resolution along with the capability for simultaneous analysis of atropine and its related degradants, impurities and formulation excipients. The method was successfully applied for the analysis of atropine and its impurities in stockpiled ATNAA auto-injector samples.

In summary, this method can be used for efficient testing control strategies as well as lifecycle management to evaluate the extended stability analysis of atropine and its respective impurities for drug products stored in the SNS. The information on extended product stability beyond expiry is unique and the use of 
advanced analytical technologies such as UHPLC will provide greater scientific and regulatory understanding of failure and evaluating risk for stockpiled products.

\section{Acknowledgements}

This project was supported in part by intramural CDER Office of Testing and Research funding.

\section{References}

[1] Lyon, R., et al. (2006) Stability Profiles of Drug Products Extended beyond Labeled Expiration Dates. Journal of Pharmaceutical Sciences, 95, 1549-1560. https://doi.org/10.1002/jps.20636

[2] Cantrell, L., et al. (2012) Stability of Active Ingredients in Long-Expired Prescription Medications. Archives of Internal Medicine, 172, 1685-1687. https://doi.org/10.1001/archinternmed.2012.4501

[3] Khan, S.R., Kona, R., Faustino, P.J., Gupta, A., Taylor, J.S., Porter, D.A., et al. (2014) United States Food and Drug Administration and Department of Defense Shelf-Life Extension Program of Pharmaceutical Products: Progress and Promise. Journal of Pharmaceutical Sciences, 103, 1331-1336. https://doi.org/10.1002/jps.23925

[4] Khan, S.R., Mohammad, A., Khan, M.A. and Faustino, P.J. (2016) Critical Importance and Quality Evaluation of Drug Delivery Autoinjectors in the FDA-DOD Shelf Life Extension Program (SLEP). The AAPS Journal, 18, 801-803. https://doi.org/10.1208/s12248-016-9910-5

[5] Dix, J., Weber, R.J., Frye, R.F., Nolin, T.D., et al. (2003) Stability of Atropine Sulfate Prepared for Mass Chemical Terrorism. Journal of Toxicology: Clinical Toxicology, 41, 771-775. https://doi.org/10.1081/CLT-120025341

[6] Rebmann, T., Clements, B.W., Bailey, J.A. and Evans, R.G. (2009) Organophosphate Antidote Auto-Injectors vs. Traditional Administration: A Time Motion Study. The Journal of Emergency Medicine, 37, 139-143. https://doi.org/10.1016/j.jemermed.2007.09.043

[7] Namba, T. and Hiraki, K. (1958) PAM (Pyridine-2-Aldoxime Methiodide) Therapy for Alkyl-Phosphate Poisoning. Journal of American Medical Association, 166, 1834-1839. https://doi.org/10.1001/jama.1958.02990150030007

[8] Gunderson, C.H. and Lehmann, C.R. (1992) Nerve Agents: A Review. Neurology, 42, 946-950. https://doi.org/10.1212/WNL.42.5.946

[9] Vijayaraghavan, R. and Jain, N. (2007) Evaluation of the Antidotal Efficacy of Atropine Sulphate and Pralidoxime Chloride Given by Autoinjectors against Nerve Agent (Sarin) Toxicity. Journal of Medicine C.B.R. Def., 5, 1-12.

[10] Vijayaraghavan, R. and Bhaskar, A.S.B. (2012) A Convenient First Aid Kit for Chemical and Biological Agents and Radiation Exposure. Journal of Environmental Biology, 33, 673-681.

[11] Namba, T. (1971) Poisoning Due to Organophosphate Insecticides. Acute and Chronic Manifestations. American Journal of Medicine, 50, 475-492. https://doi.org/10.1016/0002-9343(71)90337-8

[12] Schroeder, A.C. (1989) Pralidoxime Chloride Stability-Indicating Assay and Analysis of Solution Samples Stored at Room Temperature for Ten Years. Journal of Pharmaceutical Sciences, 78, 132-136. https://doi.org/10.1002/jps.2600780212 
[13] Schier, J.G. (2004) Preparing for Chemical Terrorism: Stability of Injectable Atropine Sulfate. Academy of Emerging Medicine, 11, 329-334. https://doi.org/10.1111/j.1553-2712.2004.tb01447.x

[14] Loch, M. (2007) Atropine Degradation Products and Trace Heavy Metal Content in AtroPenW and ComboPenW Auto-Injectors. Toxicology, 233, 229-230. https://doi.org/10.1016/j.tox.2006.04.015

[15] O’Neil, M.J. (2006) The Merck Index. 14th Edition, Merck and Co., Whitehouse Station, 873.

[16] Kirchhoff, C., Bitar, Y., Ebel, S. and Holzgrabe, U. (2004) Analysis of Atropine, Its Degradation Products and Related Substances of Natural Origin by Means of Reversed-Phase High-Performance Liquid Chromatography. Journal of Chromatography $A, 1046,115-120$. https://doi.org/10.1016/j.chroma.2004.05.088

[17] Von, R.V. (1900) Organic Chemistry. Carbocyclic and Heterocyclic Series, 11, 681682.

[18] Van Der Meer, M.J. (1983) Preparation of Noratropine by Oxidative N-Dmethylation of Atropine. Journal of Pharmacy and Pharmacology, 35, 408. https://doi.org/10.1111/j.2042-7158.1983.tb02975.x

[19] Gören, A.C. (2004) Simple High-Performance Liquid Chromatographic Method for Determination of Atropine and Obidoxime in a Parenteral Injection Device. Journal of Chromatography A, 1057, 237-239. https://doi.org/10.1016/j.chroma.2004.09.048

[20] Lau, O.W. and Mok, C.S. (1997) High-Performance Liquid Chromatographic Determination of Atropine and Atropine-Like Alkaloids in Pharmaceutical Preparations with Indirect Conductometric Detection. Journal of Chromatography A, 766, 270-276. https://doi.org/10.1016/S0021-9673(96)01019-9

[21] Paddle, B.M. and Dowling, M.H. (1993) Simple High-Performance Liquid Chromatographic Method for Assessing the Deterioration of Atropine-Oxime Mixtures Employed as Antidotes in the Treatment of Nerve Agent Poisoning. Journal of Chromatography A, 648, 373-380. https://doi.org/10.1016/0021-9673(93)80419-9

[22] Pohjola, J. and Harpf, M. (1994) Determination of Atropine and Obidoxime in Automatic Injection Devices Used as Antidotes against Nerve Agent Intoxication. Journal of Chromatography $A, 686,350-354$. https://doi.org/10.1016/0021-9673(94)00780-2

[23] Takahashi, M. (1997) Determination of Atropine in Pharmaceutical Preparations by Liquid Chromatography with Fluorescence Detection. Journal of Chromatography $A$, 775, 137-141. https://doi.org/10.1016/S0021-9673(97)00305-1

[24] Walters, M.J. (1978) High Pressure Liquid Chromatographic Determination of Atropine Sulfate and Scopolamine Hydrobromide in Tablets. Journal-Association of Official Analytical Chemists, 61, 1428-1432.

[25] Zimmermann, T. (2012) Rapid Resolution Liquid Chromatography for Monitoring the Quality of Stockpiled Atropine Preparations for Injection. Drug Testing and Analysis, 4, 222-228. https://doi.org/10.1002/dta.402

[26] Chandarana, C. (2016) UPLC: A Prominent Analytical Technique for Pharmaceuticals. International Journal of Pharmaceutical Sciences Review and Research, 37, 192-201.

[27] Chen, H.X., Chen, Y., Du, P. and Han, F.M. (2007) LC-MS for Identification and Elucidation of the Structure of In-Vivo and In-Vitro Metabolites of Atropine. Chromatographia, 65, 413-418. https://doi.org/10.1365/s10337-007-0187-9

[28] Russo, R. (2008) Pharmaceutical Applications on Columns Packed with Sub-2 $\mu \mathrm{m}$ Particles. Journal of Chromatographic Science, 46, 99-208. 
https://doi.org/10.1093/chromsci/46.3.199

[29] Nguyen, D.T. (2006) Fast Analysis in Liquid Chromatography Using Small Particle Size and High Pressure. Journal of Separation Science, 29, 1836-1848. https://doi.org/10.1002/jssc.200600189

[30] Mazzeo, J.R. (2005) Advancing LC Performance with Smaller Particles and Higher Pressure. Analytical Chemistry, 77, 460A-467A. https://doi.org/10.1021/ac053516f

[31] Villiers, A.D. (2006) Evaluation of Ultra Performance Liquid Chromatography: Part I. Possibilities and Limitations. Journal of Chromatography A, 1127, 60-69. https://doi.org/10.1016/j.chroma.2006.05.071

[32] Wren, S.A.C. (2006) Use of Ultra-Performance Liquid Chromatography in Pharmaceutical Development. Journal of Chromatography A, 1119, 140-146. https://doi.org/10.1016/j.chroma.2006.02.052

[33] Arvadiya, A.C. (2013) Development and Validation of Novel RP-UPLC Method for Estimation of Atropine Sulphate in Pharmaceutical Dosage Form. Chemical Industry \& Chemical Engineering Quarterly, 19, 333-337. https://doi.org/10.2298/CICEQ120319068A

[34] USP 39-NF 34 (2016) United States Pharmacopeia 1225 Validation of Compedial Procedures. USP, 1-10.

[35] USP 39-NF 34 (2016) United States Pharmacopeia 621 Validation of Compedial Procedures. USP, 1-7.

Submit or recommend next manuscript to SCIRP and we will provide best service for you:

Accepting pre-submission inquiries through Email, Facebook, LinkedIn, Twitter, etc. A wide selection of journals (inclusive of 9 subjects, more than 200 journals)

Providing 24-hour high-quality service

User-friendly online submission system

Fair and swift peer-review system

Efficient typesetting and proofreading procedure

Display of the result of downloads and visits, as well as the number of cited articles

Maximum dissemination of your research work

Submit your manuscript at: http://papersubmission.scirp.org/

Or contact pp@scirp.org 